\title{
Getting It Right from the Beginning: IMAGINATION AND EDUCATION IN John Dewey and Kieran Egan
}

\section{Davide Weible}

\section{INTRODUCTION}

John Dewey's theory of education, despite having become a reference point for the pedagogical sciences, has been subjected to much criticism. One of the most significant attacks came from Jerome Bruner (1962), who questioned Dewey's principles as set forth in his "My Pedagogic Creed" (1897). ${ }^{1}$ Bruner chose that book for criticism because it foreshadowed much of the later writing on education by the American philosopher, and he assessed the five articles of faith contained therein against the background of the deep changes that had occurred in conceptions of society, social institutions, and man. Then, paralleling Bruner, Kieran Egan (2002) stressed more recently the necessity to reconsider some of Dewey's presuppositions from the viewpoint of contemporary advances in understanding, especially where new discoveries and theories in the developmental psychology of children are concerned. ${ }^{2}$

On the other hand, there have also been attempts to give new life to Dewey's legacy. As for his greatest educational work, Democracy and Education (1916), Hansen (2006) has edited a collection of essays that engage critically with its contents and provide examples of how one might make use of them today in research and practice. ${ }^{3}$ Having been the most translated of all Dewey's works, and having become popular in such different contexts as educational research, humanities, social sciences, and many others, it is a classical text in I. Calvino's sense, that is, something that has never finished saying what it has to say and will always provide insights and suggestions, as well as fostering debates and critiques.

Without disputing Bruner's and Egan's approaches and denying the value of their remarks, the present research focuses on one aspect of Dewey's teaching methodology - the role of imagination - that, though not fully developed into a coherent theory within his writings on education, and hence underestimated in the subsequent secondary literature, stands up to criticism and still proves to be viable. In the second section of the article I outline the contours of Dewey's "problem of education," as explicated in Democracy and Education, and explain how his learning by doing pedagogy originated as an appropriate solution, and, at the same time, is consistent with his general theory of language and meaning. In the third section I review the few but important passages where, within this classical work, the use of 
mental images by learners is recognized as necessary for the proper understanding of contents. Subsequent to this, works other than Democracy and Education are considered in order to better clarify the nature of imagination and its connection with other aspects of child psychology operative in the educational setting. Further imaginative processes are described in section four so as to broaden, as much as possible, the set of elements to draw on after in the comparative analysis. In order to demonstrate the present-day validity of these ideas, in the fifth section I summarize the core of Egan's criticism of Deweyan activism and progressivism-indeed, one of the most effective negative assessments-and show how his methodological proposal is built on the attribution of a key function in imagination, both in the cognitive development of children and in the teaching practices of educators. From this perspective, and quite paradoxically, the former's theory turns out to be indirectly one of the best corroborations of the latter's conclusions. Finally, the conclusion sums up briefly the achievements of the paper, suggests two connections that are worth considering from a historical-comparative viewpoint (they can possibly provide, as research prospects, further interdisciplinary support for Dewey's claims), and dwells on some key theoretical points concerning the way the two pedagogues understand the ability to imagine.

\section{Dewey's "Problem of Education” and Its SOlution}

In Democracy and Education (1916), Dewey maintains that the historical development of democracy as a kind of social life has led to a contradiction between what a society believes and what it actually does. On the one hand, modernity-the experimental method in the sciences, the biological theory of evolution, and the industrial reorganization-has seen the progressive achievement of the democratic values of multiple shared interests and broad communicative interaction. On the other hand, the way they are put into practice within the schooling system is contradictory and frustrates education itself, whose function is "discovering and developing personal capacities, and training them so that they would connect with the activities of others" (Dewey 1916, 104). If the concept of democracy implies the constitution of a social system based upon such values as collaboration, solidarity, initiative, and common interests, education concerns instead the moral and intellectual development of citizens able to embody and perpetrate them.

In a more fundamental sense, for Dewey $(1916,1-7)$, education is the process of the transmission of experience by means of communication through which a social group ensures the continuity of its existence. The absence of a genetic codification of social information and its distribution in an increasing set of cultural-artificial carriers, along with the extremely high degree of biological and psychological immaturity of human newborns, require the creation of a special environment for that transmission to be accomplished. Hence, the educational setting consists of a relational sphere mediating direct contact with inhospitable surroundings as well as complex and 
extensive cultural contexts. The biological aspect of the gap- "[t]he young of human beings compare so poorly in original efficiency with the young of many of the lower animals, that even the powers needed for physical sustentation have to be acquired under tuition" $(1916,4)$-calls for prolonged parental care, while the cultural distance (in terms of the quantity and quality of knowledge) can be reduced in two ways.

First, a solution is provided by informal and direct participation in working activities, everyday practices, and rituals of the social group; this type of education does not pertain to "savage" societies exclusively, but rather it is the primary ground for the persistence of any kind of association, whatever the reason for its coming into existence. In Dewey's words, it is "the education which every one gets from living with others, as long as he really lives instead of just continuing to subsist" (1916, 7), and encompasses such groups as "[a] clique, a club, a gang, a Fagin's household of thieves, the prisoners in a jail ... a church, a labor union, a business partnership, or a political party" (25) and so forth.

Second, a formal, indirect, and deliberate type of education is required whenever the complexity of the group widens to the extent that simple imitation can no longer be effective in transmitting knowledge. Its indirectness lies in the logical and spatial remoteness of adults' actions, which presuppose such a large amount of prior knowledge that spontaneous immediacy becomes counterproductive. Its formality consists in the substitution of physical distance by symbolic reference and in the fact that experience is provided in a logical-hierarchical manner. Its intentionality, finally, is partly due to the written nature of the storage of information: "written symbols are even more artificial or conventional than spoken; they cannot be picked up in accidental intercourse with others" (Dewey 1916, 22-23), and therefore they need to be communicated in a deliberately designed setting. With this kind of education, "intentional agencies-schools-and explicit material-studies—are devised. The task of teaching certain things is delegated to a special group of persons" (9).

Because of the peculiar processes occurring inside it, school constitutes for Dewey a special environment endowed with three functions, with respect to the world of adults: (1) simplification of knowledge, (2) selection of features, and (3) multiplication of influences. However, since it implies a modelling context and not the original dimension of experience, "formal instruction ... easily becomes remote and dead-abstract and bookish, to use the ordinary words of depreciation" (9). As a matter of fact, "one of the weightiest problems with which the philosophy of education has to cope is the method of keeping a proper balance between the informal and the formal, the incidental and the intentional, modes of education" (10).

This mediation is geared toward the proper natural development of "thinking" and "learning," which in turn meet the primary requirement of education by allowing the raising of democratic citizens. Faithful to his pragmatic and instrumental philosophy, and in direct reference to his account of experience, Dewey conceives thinking as "the accurate and deliberate instituting of connections between what is done and its consequences" $(1916,177)$. More specifically, it includes "these steps, - the sense 


\section{DAVIDE Weible}

of a problem, the observation of conditions, the formation and rational elaboration of a suggested conclusion, and the active experimental testing" (177). Proper thinking results in actively and spontaneously learning solutions for problematic situations; besides, both activities rest on a more primitive and foundational moment that, on the methodological plane of concrete teaching, takes on an equally pivotal role: "the necessity of an actual empirical situation as the initiating phase of thought. Experience is here taken as previously defined: trying to do something and having the thing perceptibly do something to one in return" (180; emphasis mine).

To conclude this brief overview of Dewey's "problem of education," a clear contradiction emerges between democratic ideals and conventional teaching practices, and its solution consists in active learning and the development of educational environments based on experimental-manipulative methods. That is, on the one hand, "the material of thinking is not thoughts, but actions, facts, events, and the relations of things" (1916, 184); and, on the other hand, "the physical equipment and arrangements of the average schoolroom are hostile to the existence of real situations of experience" (182). Accordingly, "where schools are equipped with laboratories, shops, and gardens, where dramatizations, plays, and games are freely used, opportunities exist for reproducing situations of life, and for acquiring and applying information and ideas in the carrying forward of progressive experiences" (190).

The "learning by doing" formula, which synthesizes this overall approach, translates into several prescriptions for the study of, for instance, arithmetic, geometry, physics, history, and geography. More precisely, it applies to the whole domain of symbolic representation, and this approach presupposes, in turn, a specific theory of language and meaning. For Dewey, symbols (like words) are sensible things that stand for, detach, and preserve meanings only insofar as someone was able to experience these meanings through direct interaction with reality; that is why "to attempt to give a meaning through a word alone without any dealings with a thing is to deprive the word of intelligible signification" (Dewey 1910, 176). ${ }^{4}$ The common consent that defines the representative and communicative functions of language is that of "agreement in action" (Dewey 1938/1939, 46): 5 people use symbols and understand each other only because they refer them to real public activities and their actual consequences, so that "the meaning which a conventional symbol has is not itself conventional" (47). This "concord of consequences," as the determinant of signification for anything utilized as a medium of communication, implies that to understand words is to identify the meanings of objects and events they are used with, which, in turn, can be defined as follows: "familiar acquaintance with meanings ... signifies that we have acquired in the presence of objects definite attitudes of response which lead us, without reflection, to anticipate certain possible consequences" (Dewey 1910, 125).

Such considerations on the nature of meaning and its symbolic transmission already bring into play implicitly the role of imagination in two interconnected ways. On the one hand, images of objects and events, along with the practical 
activities and results they entail, are retained in association with symbols; on the other hand, they are the means by which "expository definitions" of new meanings, socially and pedagogically valuable, are provided to pupils:

Given a certain store of meanings which have been directly or denotatively marked out, language becomes a resource by which imaginative combinations and variations may be built up. A color may be defined to one who has not experienced it as lying between green and blue; a tiger may be defined (i.e., the idea of it made more definite) by selecting some qualities from known members of the cat tribe and combining them with qualities of size and weight derived from other objects. (1910, 132; emphasis mine)

The simplicity of Dewey's examples should not mislead, since the cognitive function described above can be extended to the intellectual dimension as a whole. When Dewey characterizes thinking as the deferment of organic-biological activities, so that it is possible to rehearse by symbolic representation the course of behaviors and modify or avoid results that, if openly manifested but not desirable, would be irretrievable, he qualifies it as "a rudimentary form of reasoning in connection with solution of problems” (Dewey 1938/1939, 57). Even more radically, writes Dewey, "I would say that I am not aware of any so-called merely 'mental' activity or result that cannot be described in the objective terms of an organic activity modified and directed by symbols-meaning, or language, in its broad sense" (57). When it comes to moral deliberation, for example, imagination is directly referred to: "As matter of fact, it is a process of tentative action; we 'try on' one or other of the ends, imagining ourselves actually doing them, going, indeed, in this make-believe action just as far as we can without actually doing them" (EW 4, 251; emphasis mine). ${ }^{6}$

Moreover, Dewey says, if "we continue to react to an object presented in imagination as we react to objects presented in observation" (Dewey 1922/1928, 199), ${ }^{7}$ then from a pragmatic viewpoint there is no "solution of continuity" between perception, action, and imagination, and, what is more, actual and rehearsed activities and results cannot be distinguished insofar as their meaning is concerned. From a pedagogical perspective, that entails that learning by doing and learning by imaging are cognitively and methodologically analogous and need to be pursued together.

\section{A Complementary Solution: The Role of Imagination}

In Democracy and Education, there are several positive references to children's mental imagery, though they are mentioned in relation to other topics and not gathered together in a single section. In the first place, while explicating the communicative function of language as a means of teaching and learning, Dewey grounds its ability to convey ideas partially on the imaginative involvement it provides: as seen earlier, to understand or fix the meaning of words and concepts is to be engaged pragmatically in those situations 
they are associated with. Therefore, "the use of language to convey and acquire ideas is an extension and refinement of the principle that things gain meaning by being used in a shared experience or joint action" (Dewey 1916, 19). Above all, "when words do not enter as factors into a shared situation, either overtly or imaginatively, they operate as pure physical stimuli, not as having a meaning or intellectual value" (19; emphasis mine).

Due to the constraints that tend to characterize formal education-complexity of the subject matter, impossibility of direct imitation, symbolic language-Dewey's reasoning can be extended to the point of claiming that much of what happens during formal education with pupils finds its condition of possibility in their ability to imagine. When giving advice on how to help them learn geography effectively, for instance, he points out that, as a discipline that "originally appeals to imagination" $(1916,248)$, it turns into a simple storehouse of scattered facts any time "imagination is not fed, but is held down to recapitulating, cataloguing, and refining what is already known" (248-49).

In the second place, Dewey acknowledges the function of images in his discussion of educational values. To begin, he puts the notions of "appreciation" and "realization" in connection with the idea of "interest," previously defined in several ways: one's being "bound up with the possibilities inhering in objects" $(1916,146)$; they are "attitudes toward objects - toward what is foreseen" (147); an interest "represents the moving force of objects-whether perceived or presented in imagination-in any experience having a purpose" (152-53; emphasis mine). Then, he defines them in terms of "the difference between reading a technical description of a picture, and seeing it . . between learning mathematical equations about light and being carried away by some peculiarly glorious illumination of a misty landscape" (272-73); that is, between direct and indirect experience. On this basis, it follows that "imagination is the medium of appreciation in every field. The engagement of the imagination is the only thing that makes any activity more than mechanical" (276; emphasis mine).

Eventually, after having established that the contrast between childish fantasies and adult occupations is not a function of the presence or absence of imagination, but rather regards a difference in the materials with which images are occupied, Dewey fully endorses its primary (and not merely subsidiary) role:

An adequate recognition of the play of imagination as the medium of realization of every kind of thing which lies beyond the scope of direct physical response is the sole way of escape from mechanical methods in teaching. The emphasis put in this book, in accord with many tendencies in contemporary education, upon activity, will be misleading if it is not recognized that the imagination is as much a normal and integral part of human activity as is muscular movement. (1916, 277; emphasis mine)

The fundamental principle of Dewey's pedagogy—activism—is intrinsically tied to imagery because of its intellectual propensity toward generalization: "were it not for the accompanying play of imagination, there would be no road from a 
direct activity to representative knowledge" (1916, 277-78). Before Democracy and Education, this point had already been expressed, for instance, in the observation that often in primary school, pupils are kept too long handling objects: it is right not to begin with abstract formulae too early, but "the child should be led to deal as soon as possible with images" (LW 17, 248), since they detach him or her from the here and now of particular experiences and allow the extension of meanings. These passages suggest that, when insisting upon the importance of recurring to imagination given its intermediary status between concreteness and abstractness, Dewey somewhat escapes Egan's criticism, which has as one of its main polemical targets the misleading assumption in progressive education of a rigid concrete to abstract learning process in children. As I will show later, a similar appeal is exactly the strategy adopted by Egan to remedy this flaw in contemporary pedagogy. Still, Dewey and Egan manifest some disagreement with respect to the contents to be imagined: for Egan, imagination naturally feeds (also) on the fantastic and bizarre, which need to be properly stimulated right from the earliest stages of learning; for Dewey, instead, the erroneous identification of the imaginative with the imaginary has led to an "exaggerated estimate of fairy tales, myths, fanciful symbols, verse, and something labeled 'Fine Art"' (Dewey 1916, 276). Though I am not dwelling on it here, it is worth remembering that such a critique is consistently present throughout Dewey's theoretical and educational writings. ${ }^{8}$

Despite these considerations, it has been noticed that in Democracy and Education one cannot find anything more than mere hints and brief digressions concerning mental images, a fact that forces us to look elsewhere to find more indepth treatments. ${ }^{9}$ In Psychology (1887/1890) ${ }^{10}$ a detailed description of imagination is provided in the context of a general theory of the development of intelligence: it is a phase in the process of progressive idealization or symbolization of sensible data, whereby they are inserted in increasingly larger networks of meaningful relations and detached from particular spatial-temporal collocations; more precisely, it is "that operation of the intellect which embodies an idea in a particular form or image" (Dewey 1890, 192) and, unlike perception and memory, does not depend on the actual existence of objects and events. Since it is already involved in the construction of percepts and their recalling - to perceive is to supplement partial sensations and interpret them as a coherent whole, a procedure whose working and outcomes remain implicit even in the following retrieval from memory-imagination consists in "bringing to consciousness what was previously in unconsciousness" $(1890,194)$.

Dewey distinguishes different types of imaginative processes, along with diverse interests that characterize them. In the first case, once the ideal has been abstracted from the real by separating constant elements and accidental circumstances, three different kinds or stages of elaboration can occur: (1) "mechanical imagination," whereby mental representations are broken down and differently recombined; (2) "fancy," where "the formation and connection of images is controlled by an exceedingly vivacious and receptive emotional disposition" (1890, 
195); and (3) "creative imagination," whose activity is bound neither to the psychological laws of association and dissociation (first stage), nor to occasional feelings (second stage), but proceeds toward the deliberate construction of new meaningful wholes. Besides, at this level there is a further process of selective focalization, whereby idealization is followed by universalization, and specific attention is paid to the permanent and more general aspects of mental representations.

In the second case, Dewey recognizes a close connection between these operations and the interests, emotions, and aspirations of the self: "imagination, in short, takes its rise in feeling, and is directed by feeling much more explicitly than either perception or memory" $(1890,198)$. However, this relationship becomes fully meaningful only when universal interests (grounded in the common and unitary character of human life) are involved and must be thought of not just in aesthetic terms, but also from a practical and theoretical viewpoint: being a constitutive component of the development and functioning of human knowledge, imagination permeates the finest forms of artistic expression as well as the highest achievements of science and technology.

In concluding his description, Dewey points out that imagination represents "the transition from the particular stage to the universal.... Imagination deals with the universal in its particular manifestation, or with the particular as embodying some ideal meaning, some universal element" $(1890,201)$, thereby setting the ground for thinking proper. In this respect, to speak about imagination or thought implies nothing more than putting emphasis alternatively on two complementary aspects; that is, particular form and universal content. Given such a stress in Psychology on the significance of the ability to imagine for the growth of knowledge, it comes as no surprise that in his subsequent educational writings Dewey repeatedly drew attention to its centrality.

In one of his "Educational Lectures Before Brigham Young Academy," Dewey talks of imagery as "the chief instrumentality in the pupils" mind upon which the teacher has to rely" (LW 17, 242). The feature that defines its peculiarity is the power of realizing what is not present: if learning, in order to be properly accomplished, has to pass through facts and materials, "how can anyone get hold of things which are not directly present? The answer is, through this power of imagery, the power of forming mental pictures of whatever is presented" (ibid.).

After a concise typology of images-visual, auditory, and motor (movement and touch) - Dewey contrasts their utility with unreal and fantastic things, and, not unlike what he previously claimed in Psychology, puts them into connection with such more abstract cognitive processes as geometrical and arithmetical reasoning. As for the first, he elaborates on the auxiliary function of external figures to suggest the necessity of a methodology promoting mental visualization: educators should "give a little systematic practice in visualizing these figures, and so train the pupil to see these figures" (LW 17, 246). This translates into the observation that "even in abstract reasoning, a person must have an image ... if he has no images of what he is handling or thinking about he has nothing to work with mentally" (246). 
The same holds true for arithmetic, but here the scope of Dewey's analysis is broader. If in teaching geometry the use and efficacy of graphical images is wholly justified by the spatial nature of the subject matter itself (though it can be expressed by means of an algebraic notation as well), in the case of numbers his remarks refer to the general framework of pragmatism. When maintaining that children "ought not to deal with symbols unless they can be made to stand for images of some sort or other" (LW 17, 247; emphasis mine), or that "imaging is precisely the power or the instrumentality through which we translate abstract terms and symbols and formulae over into the actual conditions" (248; emphasis mine), Dewey is underlying something that, as shown previously, he will subsequently develop explicitly in his theory of language learning and linguistic meaning: the dependence of the meaningfulness of symbolic and abstract notions on situations of active experience.

By virtue of the pragmatic origin-either in direct perception or indirect construction of images-of our competence to understand and communicate words and concepts, the instrumental and substitutive function of imagination proves to be just as extensive as the usage of natural language and invests the entire curriculum, from the more concrete to the more abstract disciplines. Dewey's examples, similar to those in Democracy and Education, include geography: it "is almost entirely, one might say, a matter of the cultivation of the imagination" (LW 17, 250); physical geography: "A great many children have difficulty in understanding the theory of the winds and ocean currents because they do not image what they are talking about" (251); physics: "to understand the mechanism of a pump... (h)e would merely have to follow the direction of his own images, and simply tell what he sees from step to step" (251-52); history: "A good deal of history will remain merely verbal, unless pupils are cultivated in the power to present to themselves the personages and the scenes they are talking about" (ibid.); and literature. All these instances imply something more than simple reproductive imagery, otherwise it would be impossible to visualize mentally that which has never been seen before and to supply concrete meanings to new conceptual and verbal information. Once the pupil has acquired images from sense perception, "he must then learn how to handle these images, how to construct and reconstruct or make them over, in order to realize scenes which have never been actually presented to his senses, but only to his mind's eye" (251; emphasis mine).

Along with abstractness, the transformative aspect of imagination is what characterizes it as a form of thinking analogous to higher order processes. If reasoning is usually understood by referring to the logical structure of the syllogism, its psychological counterpart is just as much important: "I would suggest that what really goes on when we reason is that the mind starts with two truths different from each other, then, with what we call reason, these images are manipulated and finally made to run together and blend, so to speak, in another image" (LW 17,253). Conceptual and imaginative thinking seem to share a common combinatorial functioning; besides, this passage is remarkable in that it reminds of C. S. Peirce's operative concepts of iconicity and diagrammatic reasoning. ${ }^{11}$ 


\section{Further Imaginative Processes}

Before turning to Egan's position on this subject, a few observations are worth making regarding other key processes involved in learning. In some of these cases, the connection with imagination is indirect and not as clearly stressed as in the previous examples, but it can be readily inferred given the organic nature of Dewey's thought, his precise terminological choices, and his existing interpretations of commentators. This is useful in a twofold way: it further confirms the pervasiveness of imaginative thought in Dewey and significantly widens the basis on which to make a structured comparative analysis.

First of all, Dewey refers to the importance of imagery for memory. In his lecture on imagination, there were already occasional observations thereof, ranging from examples made to describe the types of images to the following statement: "If it were not for this power of imaging, the rest of the world would be blotted out. Even when we remember things we remember through images. I want to emphasize that fact; we have the power of memorizing things only as we image them" (LW 17, 246). In a subsequent lecture, titled "Memory and Judgment," Dewey elaborates on this linkage and points out that "there are many kinds of memories connected with the mental images" (LW 17,327) and "the child does not remember or memorize by the general power or faculty of memory; he does his translating over into some of this groups of images" (327-28). In concrete teaching, this means the solicitation in children of visual, auditory, or motor images in order to improve their attention and retention.

Second, in the essay "Appreciation and Cultivation" (LW 6, 112-30), after having defined "appreciation" (in its general scope as a function of normal experience) as a personal sense of value toward something and having recognized its operation in pupils' effective learning, Dewey claims that it "involves a stirring of emotion and an immediate development of imagination" (LW 6, 113); therefore, "if certain school subjects do not offer material which is appreciated, it must then be because of lack of emotional and imaginative power as these subjects are taught and learned" (ibid.). However, in the subsequent discussion of this topic in Democracy and Education, the relationship between the two components needs be extended and articulated in a twofold way: on the one hand, emotions awaken and direct imagination, so that the former represents the carrying impetus, whereas the latter "denotes that to which we are carried when the emotion is not so coarsely organic as to lead to direct overt action" (LW 6, 115-16). On the other hand, and complementarily, since children do not appreciate abstract words and concepts, but rather the activities and consequences of concrete situations they refer to, imagination both retrieves from memory and produces highly emotionally charged images that transform static contents, short of any propulsive charge, into learning experiences that are personally meaningful.

Third, imagination is also essential for ethics. For Fesmire $(2003,64)$, the contemporary renascence of the interest in their connection "has proceeded more or less in ignorance of Dewey's fecund insights," and despite his recognition that 
the former "intervenes deeply in moral life. ${ }^{12}$ It is at the foreground of deliberation and so must be central, not merely supplementary, to moral judgment" $(2003,68)$. Imagination, through a process sharing notable similarities with both the mental modification of one's own spatial collocation and the transformation of visual images, discloses the sympathetic ability to put ourselves in the place of others and see things from their viewpoint; hence, it "is the surest way to attain objectivity of moral knowledge ... because it furnishes the most efficacious intellectual [rational, universal, ideal] standpoint" (LW 7,270). Thanks to the disclosure of a mental space enabling the "vision" of others' interests and values, and allowing estimation of one's own claims and pretensions from the perspective of an impartial observer, the consequences of actions become valuable beyond simple private means-ends calculations. That is what happens when reflective thinking is applied to practical and moral issues:

Deliberation is actually an imaginative rehearsal of various courses of conduct. We give way, in our mind, to some impulse; we try, in our mind, some plan. Following its career through various steps, we find ourselves in imagination in the presence of the consequences that would follow: and as we then like and approve, or dislike and disapprove, this consequences, we find the original impulse or plan bad or good. (LW 7,275)

In educational terms, instilling in students' minds habits of sympathetic concern, imaginative projection, and controlled behavior is something worth pursuing as, on the one side, consistent with Dewey's view on the primary function of education, and, on the other side, for the development of citizens able to share the collective interests and values of associated life and democracy.

Fourth, imagination turns out to be an indispensable prerequisite for a whole series of teaching practices. It is clearly involved in storytelling, which is itself "primarily dramatic, rather than lyric, whether it takes the form of the play enacted on the stage, of the told story or silent soliloquy" (Dewey 1922/1929, 89). Dewey's appreciation for this tool appears distinctly throughout his analysis, in Schools of Tomorrow (1915), of several experimental educative approaches of his time: the best way for young people to appreciate literature, for instance, entails the reading of or being told stories and the acting out of "any tale that has appealed especially to their dramatic imagination" (Dewey and Dewey 1915, 36). Moreover, given the importance of inventing personal narratives, "children tell stories much more effectively when they are led to visualize [and perform] for themselves the actions going on, than when they are simply repeating something as a part of the school routine" $(1915,122)$. Other examples of application come from arithmetic and grammar. In one case, the setting up of a shoe store in the second grade and the writing of stories about it (which obviously requires imagining them) provided the basis for arithmetic and English lessons, and "they probably could not have gone so rapidly if they had not had so much of the dramatization work [either actually 
performed or mentally represented]. It served to make their abstract problems seem real" $(1915,123) \cdot{ }^{13}$ In short, storytelling and dramatization require images in order to be created, and they anticipate (and accompany) higher cognitive abilities:

The imaginative stories poured forth by children possess all degrees of internal congruity; some are disjointed, some are articulated. When connected, they simulate reflective thought; indeed, they usually occur in minds of logical capacity. These imaginative enterprises often precede thinking of the close-knit type and prepare the way for it. (Dewey 1910, 3) $)^{14}$

Along with storytelling, play is also a pivotal practice, and imagination participates in its construction and execution as a key component. As a matter of fact, it is possible to draw many parallels between them. Just as imagination goes beyond the here and now of actual perceptions and concrete actions, so play is not mere motor exuberance, but involves a mental factor: "when children play ... they are subordinating the physically present to the ideally signified" (Dewey 1910, 161); that is "they are living not with the physical things, but in the large world of meanings, natural and social, evoked by these things" (ibid.). Just as imagination entails insights into the future for present guidance, so play is not an end in itself, but assumes a directing function: persons who play "are trying to do or effect something, an attitude that involves anticipatory forecasts which stimulate their present responses.... The imagination makes what it will of chairs, blocks, leaves, chips, if they serve the purpose of carrying activity forward" (Dewey 1916, 238-39). Just as imagination is vicarious action originating from problematic situations or unfulfilled needs and operating distinctly in the deliberative or reflective phase of inquiry, so play has the same type of connection with reality: like art, where "conversion of direct energy into imagination is the starting point of an activity which shapes material" (Dewey 1928, 164), playing rests upon "a demand in imaginative activity for an outlet which is denied in overt activity" (163); analogously, "the ordinary course of action fails to give adequate stimulus to emotion and imagination. So in leisure time, there is an imperious demand for their stimulation by any kind of means" (Dewey 1916, 240). Eventually, just as imagination can go beyond its purely mechanical reproductive function and allow innovative solutions, so play is not simply imitative and (although also supplying conservative influences against chance) favors creativity: if, for instance, children need to build a house for a toll, "one readily sees that it has taken a great deal of hard thinking and experimenting to make a house that would really stand up and serve such uses" (Dewey and Dewey 1915, 112).

Dewey's examples-especially for the play instinct of dramatization, namely children's desire to 'act out' or "make-believe in action," of highly emotional and imaginative value-range from the teaching of arithmetic $(1915,124)$ to history (124-25) and literature (128), and many other subject areas. ${ }^{15}$ 
Two more methodological "expedients" need yet to be mentioned. First, since a healthy imaginative activity expands and fills in what is real, once projected on child's homely occupations it makes them exemplify "a wonderful world the depths of which he has not sounded, a world full of the mystery and promise that attend all the doings of the grown-ups whom he admires" (Dewey 1910, 166; emphases mine). To exercise the imagination is to construct wider experiences than the actual world, to expand it into the far and remote; by balancing the necessity to begin teaching from simple and concrete things, to imagine means to meet the unknown - this feature has to be exploited by teachers for effective and engaging learning (as will be clearer later, this saves in part the American philosopher from Egan's accusations that within progressivism children are viewed solely as concrete thinkers). Second, Dewey leans sometimes toward the educative value of making pupils appreciate the "lives of great men, of heroes and leaders, [which] make concrete and vital historic episodes otherwise abstract and incomprehensible" (Dewey 1916, 251), to be identified with "the scientific discoverers and inventors who have put into man's hands the instrumentalities of an expanding and controlled experience, and the artists and poets who have celebrated his struggles, triumphs, and defeats" (254). However brief and unsystematic, these reflections suggest the educational importance of referring to such historical figures. By imagining them and the difficult and compelling vicissitudes between successes and defeats they had to endure, children learn not only to translate a series of events into vivid pictures, but also that great and socially meaningful results can be achieved, thereby being inspired to imitate and to accomplish such results themselves.

One last point deserves attention. Although Dewey did not develop an explicit account of metaphor, there are at least two textual passages that show its pertinence for the current discussion. In the first one, the principle of continuity between organic interaction and reflective thought (central to the very definition of imagination) is reaffirmed through reference to metaphorical thinking:

Every thought and meaning has its substratum in some organic act of absorption or elimination of seeking, or turning away from, of destroying or caring for, of signaling or responding. It roots in some definite act of biological behavior; our physical names for mental acts like seeing, grasping, searching, affirming, acquiescing, spurning, comprehending, affection, emotion are not just "metaphors." (Dewey 1929, 290)

In the second passage, the connection between metaphor and imagination emerges clearly when considering the nature of aesthetic expression. During the realization of a work of art, in parallel with changes in the physical material, there occur similar transformations on the side of such "inner materials" as images, memories, and emotions. In Dewey's words, "the imagery is of the objective medium undergoing development. The physical media may be ordered in imagination or in concrete material. In any case, the physical process develops imagination, while imagination 


\section{DAVIDE WeIBLE}

is conceived in terms of concrete material" (Dewey 1980, 75). The original artistic emotion is mentally and materially reshaped by this twofold operation, and, if in its beginning it usually points straight to its object, during the following development it "may be turned aside from its direct end" (76) and reoriented toward anything that can sustain it. Metaphorical imagination is at work precisely in such a displacement:

The emotion of love may seek and find material that is other than the directly loved one, but that is congenial and cognate through the emotion that draws things into affinity ... . Consult the poets, and we find that love finds its expression in rushing torrents, still pools, in the suspense that awaits a storm, a bird poised in flight, a remote star or the fickle moon. Nor is this material metaphorical in character, if by "metaphor" is understood the result of any act of conscious comparison. Deliberate metaphor in poetry is the recourse of mind when emotion does not saturate material. Verbal expression may take the form of metaphor, but behind the words lies an act of emotional identification, not an intellectual comparison.

In all such cases, some object emotionally akin to the direct object of emotion takes the place of the latter.... This is what happens when any natural impulse is idealized or spiritualized. That which elevates the embrace of lovers above the animal plane is just the fact that when it occurs it has taken into itself, as its own meaning, the consequences of these indirect excursions that are imagination in action. (1980, 76-77; emphases mine)

With these remarks, Dewey suggests a clear affinity between metaphorical and imaginative thinking: they relate things together by being able to go beyond the given, make present what is absent, and see something as different from what it actually is. Both share a peculiar combination of cognitive features that appear to define humanity proper, and several scholars have been dwelling on this significant overlap. For Fesmire $(1999,530)$, recent work in cognitive semantics supports Dewey's claims and clarifies our ability to imagine "by studying the centrality of conventionalized metaphors in human understanding," since they determine the very horizon of possibilities displayed in imagination. For Puolakka $(2009,171)$, within the framework of neopragmatism and R. Rorty's aesthetics and philosophy of literature, it is important to realize that "Dewey's and Rorty's difference is only terminological. Rorty uses the concept of metaphor to tap into problems similar to those Dewey addresses. This is not a surprise, given that metaphor and imagination have a similar structure, namely to show something in a new light." Eventually, for Johnson (2010, 140), abstract concepts are defined by multiple and inconsistent metaphors rooted in concrete sensorimotor experiences, and Dewey "appears to have glimpsed just such imaginative processes as crucial to abstract thought ... he recognized the metaphorical character of our abstract concepts." 


\section{Egan's Imaginative EdUCATION}

The previous sections have shown that the idea of a teaching practice relying on children's capacity to imagine can be derived from Dewey's writings: learning by doing and learning by imaging are complementary and mutually interacting phases of knowledge acquisition to be equally utilized by educators. This is also consistent with existing analyses of the role of imagination in pragmatism and in Dewey's education theory. ${ }^{16}$

However, in principle this issue must be subjected to the same examination that its general framework of reference (with which it is organically linked) has undergone since its original proposal, so that, hypothetically, a negative assessment of the latter would cast doubt on and impact any attempt to suggest the present-day methodological validity of Dewey's account of imagination. All of the above might therefore have just a historical value, devoid of any possible interest or connection to current theories. What I am going to show, on the contrary, is that one of the strongest living critics of progressivism in education is proposing an alternative approach that, very much in Dewey's terms, entails acknowledgment of a pivotal role to imagination, thereby indirectly supporting the very same position that is its polemical target. Before dwelling on the places where their thoughts intersect and overlap, however, a brief review of this critique is required in order to illustrate its sense and scope, and to understand the theoretical background of the similarities.

In his book Getting It Wrong From the Beginning (2002), K. Egan puts forward the following thesis: at the core of the revolutionary 1890s for American education, which witnessed a conceptual transformation that would shape modern forms of progressivism and conceptions of pedagogy, lies the work of Herbert Spencer. His central assumption was that "to educate children effectively it is vital to attend to children's nature, and particularly to their modes of learning and stages of development, and to accommodate educational practice to what we can discover about these" (Egan 2002, 5). On this basis, psychologists should provide insights into the mental development and learning abilities of pupils, and educators should design teaching methods and contents accordingly.

Spencer's "powerful educational ideas" about learning, development, and curriculum were elaborated by Dewey and Piaget, and they found their way into current principles and practices by means of this mediation. However, these ideas "have been wrong from their beginning and haven't become any less wrong for a century's reiteration" (Egan 2002, 9); besides, "the persistence of powerful progressivist ideas continues to undermine our attempts to make schooling more effective" (8). Egan's project therefore takes the shape of a radical revision aimed at developing and putting into practice an alternative to this misleading inheritance. Roughly, it can be divided in a theoretical critique and a methodological proposal.

As for the pars destruens, Egan challenges several standard beliefs that have come to crystallize over the years in the form of "idols" of Spinozan memory, all of which share a prejudicial nature with respect to progress in the pedagogical sciences. At first glance, they might seem like principles of common sense, but with deeper inquiry they turn out 
to be wrong: "claims that children should begin with the concrete and simple are misleading ... we should cease to believe that students should begin with what they know ... we should discard such principles as preferring active to passive learning ... the long opposition to rote learning has been a disaster" (Egan 2002, 53-54). Despite a longstanding persistence and indubitableness, it is not difficult to acknowledge their flaws today.

First, the belief in a single undifferentiated development-a simple to complex learning process - can no longer be held in light of recent developments in cognitive psychology, which suggest instead modularity and multiple intelligences. Thus, "the first flaw in progressivism ... is the belief that human beings have a mode of learning whose paradigm form is evident in the way young children effortlessly learn language and other knowledge of the world in informal settings" (Egan 2002, 59).

Second, the belief in a concrete to abstract learning process, which "remains, as far as I can see, almost universally believed by teachers and is constantly reiterated in textbooks" (60), is wrong because these two terms are far from being useful in classifying and discriminating features of children's learning and thinking. "How can the characterization of young children as "concrete" thinkers survive the evidence of their ready grasp of symbols? Symbols are abstract... . By age four, children who are exposed to symbols do not confuse writing, numbers, and drawings, for example" (61).

Third, as for the most influential among these principles-the necessity of a known to unknown learning process - it is a mixture of useless analytical truth and lacks a reliable empirical generalization. Besides, it rests upon the conviction that what children know best and first is simple, concrete, and engaged with daily experience. But, Egan asks, "if children's mind are supposed to be restricted to everyday details of their social lives, why are they full of monsters, talking middle-class rabbits, and titanic emotions?" $(2002,64)$.

Fourth, the prescription for active learning has been misunderstood and turned into favoring effortless and pleasurable activities that trivialize early education. Moreover, "active" and "meaningful" might be distinguishing categories at a surface level, but they lose effectiveness at a deeper one: "Who on earth could be against active, meaningful learning and in favor of passive, meaningless learning? .... [But] is the child sitting and reading active or passive? Is the child imaginatively transported by a story the teacher is telling active or passive?" (Egan 2002, 65-66).

Egan comments on further presuppositions, but these four are enough to realize Dewey's responsibility for and contribution to the negative scenario just depicted. This “doesn't mean, of course, that Dewey merely echoes Spencer .... Dewey had his own agenda, which went in directions quite different from Spencer's" (Egan 2002, 48); nevertheless, there are striking points of contact: both shared the idea that children start learning from empirical contents and can handle only simple, practical, and local knowledge; both believed in the distinction between spontaneous, natural, and familiar everyday interactions on one side and artificial school instruction on the other side; finally, both thought that there is a natural, progressive, and orderly process of mental development leading to adult rationality. 
As for the constitution of the curriculum, Spencer and Dewey rallied in the same way for the prevalence of topics oriented toward existing aspects of social life, the avoidance of history that was not economic, industrial, and intellectual, and the primary importance of science. In general, both argued for a reduction, simplification, and concretization of the curriculum for young children. For Egan, however, once translated into concrete practice, such an educational process prevents pupils from acquiring the prerequisites for later learning: "this trivialization that begins in the early years has an impoverishing effect on students' abilities to learn throughout their schooling" $(2002,143)$. Spencer and Dewey diagnosed the problem correctly-inertia of school knowledge-but provided a faulty solution: the application of the criterion of utility as a defining feature of what is meaningful, active, and worth teaching cannot help but reduce the role of the arts, humanities, and history, thereby fostering "an unforgivable ignorance."

Clear evidence of the negative effects associated with such pedagogical beliefs can be seen in that by "deploying this set of ideas we get the elementary social studies curriculum that has been largely unchanged since the early decades of the twentieth century" (Egan 2002, 111). The result is unequivocal: "the social studies are the least effective educationally of any of the basic areas taught in the American public schools" (112). For Egan, there is only one conclusion that can be drawn: "How can the subject that most directly embodies Spencer's and Dewey's principles be such a mess in practice? Easy-the principles are wrong" (ibid.).

Faced with such an overall assessment-"the source of these ideas was a false cosmology, transformed into a mistaken evolutionary theory, converted into a flawed psychology, and then inferred into those misleading educational principles" (Egan 2002, 62) - reference to Dewey in proposing an educational methodology based on the effectiveness of images would seem to suffer in advance from the same flaws undermining contemporary theories of active and progressive learning. However, two things must be noted. First, the American philosopher was already well aware of the problems related to progressivism: in Experience and Education (1938) he warned against the dangers of a type of schooling that, because of overreaction against old and rigid teaching methods, was emphasizing individualism and a flawed conception of freedom, thereby misinterpreting and trivializing his own ideas; rather, progressivism had to be grounded on a more accurate philosophical theory of experience. Second, on the basis of what developed in the pars construens of his project, Egan himself reveals that the proposed reference is not misdirected at all, and it is my purpose in the following pages to consider one by one the features and applications of imagination previously outlined in the third and fourth sections, and to show how they are emphasized by him, as well. For expository reasons, attention will be paid to those aspects in this order: emotion, storytelling, empathy, mental imagery, embodiment of abstract ideas, memory, metaphor, play, mystery, heroes, merging of old and new experiences, and the creation of larger meaningful wholes.

Volume 31 (2) 2015 
Egan's main objective is to remold current teaching practices in accordance with recent findings in learning theory and developmental cognitive psychology: since "problems about how to educate people have been tied up with our being unsure of what the mind is," the challenge is then "to present a more adequate notion of the mind ... and to provide a set of prescriptions for properly educating such minds" (Egan 2008, 38). By drawing upon the thought of several authors, ${ }^{17}$ he elaborates on the peculiarity of human cognition-it is coextensive to culture, understood as the external store of symbolic material-to define the rationale of his method: if cultural tools extending, amplifying, modifying, and substituting thinking make their appearance with symbols, then education must be seen as "a process of maximizing our cognitive tool kit . . . a process of enlarging our understanding as far as possible given the tools our culture has developed" (Egan 2008, 43). ${ }^{18}$

Our cultural "storehouse" depends upon five "operating systems" or types of codification of information (in turn reflecting kinds of understanding) that, in order to be properly mastered, need to be acquired sequentially, since the former types are preparatory to the latter. Two complementary assumptions inherently define such sequencing: on the one hand, "the acquisition of the main cognitive tools ... [is] crucial to the stimulation and development of imagination" (Egan 2005, 8); on the other hand, the power to imagine itself is the condition of possibility of an adequate growth of the coding systems, especially those from which cognitive development begins and proceeds.

The first operating system is called somatic understanding (Egan 2008, 43-50), and its working principles coincide with those highlighted by cognitive linguistics (and by Dewey himself): the primary meanings of our experience of the world are built on a bodily and perceptive basis; besides, "these foundational interactions are pervasively emotional" (2008, 46; emphasis mine), and "the stimulation and development of the tool kit of somatic understanding ... does not cease to function as language develops but remains to be developed throughout life" (47). The implications for education are clear: since perceptions and emotions do not just represent temporary periods of our codification of knowledge, to be replaced by later, more abstract and rational forms, but rather will always be of pivotal significance, then "throughout life, stimulating the senses, humor, and the emotions remains an important part of educating" (48).

Although at this level (corresponding to infancy) imagination is not expressly mentioned and its discussion is reserved for subsequent developmental phases, its relevance is already clear. Owing to the close relation to perception, images will always be chief instruments for emotional arousal in all those occasions where direct experiential situations are inevitably missing because of the constitutive constraints of childhood and school environments. An explicit statement of this connection can be found, for instance, in Egan:

Mental imagery is a tool of immense emotional importance, influencing us throughout our lives. In societies saturated by visual images . . . it is perhaps increasingly important to allow students space to learn to

\section{E\&C Education and Culture}


generate their own mental images. We can easily forget the potency of our unique images generated from words. Often the image carries more imaginative and memorable force than the concept alone can hold. Together they can be even more potent. (2005, 4; emphases mine)

This point is very similar to Dewey's acknowledgement of the importance of cooperation between imagery (and imagination in a broader sense) and emotion in making subjects of study engaging to pupils. If somatic understanding finds a parallel in imaginative understanding, then Egan's motto- "we perceive, feel and think together" (Egan 2008, 46) - can be turned into "we imagine, feel and think together." Even more clean-cut is their common recognition that a distinctive function of the fully deployed imagination - the designing of anticipatory mental representations-is already operative at this basic corporeal and emotive level. Just compare the following excerpts (Dewey's and Egan's, respectively):

Thinking begins as soon as the baby who has lost the ball that he is playing with begins to foresee the possibility of something not yet existing-its recovery; and begins to forecast steps toward the realization of this possibility, and, by experimentation, to guide his acts by his ideas and thereby also test the ideas. Only by making the most of the thought-factor, already active in the experiences of childhood, is there any promise or warrant for the emergence of superior reflective power. (Dewey 1910, 66; emphases mine)

If you are sitting next to a one-year-old and a cat and you point at the door, the toddler will usually look at the door and the cat will look at your finger. The toddler will also point to things, something the cat, or a chimpanzee, will not do. We very early develop the power to read the intentions of others in their actions and anticipate their reading ours in our actions. We represent the world in the mind, and relate to the external world so composed in the mind, in a way that is unique among our fellow animals. (Egan 2008, 49; emphasis mine)

The link with imagination — and the resulting proximity between the two authors' ideas-is more evident in the next cognitive operating system, mythic understanding $(2008,50-62),{ }^{19}$ which extends approximately from learning to speak to the acquisition of literacy, and where children discover the possibility to generate images using words. As for the early development and acquisition of language, Egan asks, "what do these constituents of oral language that program our brain look like and how do they generate a distinctive kind of understanding?" (51). At this stage, storytelling is a specific modality of interpreting experience and processing information that exploits narrative structures (i.e., temporal sequences leading to an end) to confer emotional meanings on facts and events; hence, there follows the usefulness of its educational application in setting up imaginatively engaging lessons: "The story form can help us to bring out clearly for children the wonder of the real world and help them to see and feel that wonder" $(2008,53)$. 
What really matters here is not so much the fictionalization of subject matter, but rather the formal aspect of their organization: "the story is more a matter of the shape one gives to the content than of whether it is true or not" (Egan 2005, 12). Several cognitive advantages result from this (Egan 2008, 54): to wit, (1) making children familiar with a wide number of stories and the different ways they work helps improve the flexibility of the mind; (2) learning to construct one's own narrative, instead of just listening to others, increases creativity and personal initiative in conferring meanings on events; and (3) narrations, since they often presuppose and elicit identification, thereby intimately suggesting what it might be like to be someone else, also enlarge sympathetic understanding of others and take on a great socio-educational function. Imagination, in cooperation with them, "provides the conceptual glue that binds people together in society and generates their sense of solidarity and identity" $(2008,58)$. Eventually, despite mainstream beliefs about progressivism and the predominance of a concrete to abstract learning process, children's stories do rest on extensive abstractions and generalizations: "consider the foundations of those Grimm fairy stories-security/fear, courage/cowardice, good/bad: what more abstract ideas have you ever learned? Think also of the characters - they are not people in any rounded sense but representatives of beauty, simplicity, greed, terror, goodness, and so on" (55).

Because of its affecting power, imagery is obviously pivotal within the narrative dimension in two senses (Egan 2005, 26-28). First, it aids memorization, so that the more stories generate vivid and moving images, the more they are likely to be listened or read with interest (and hence remembered). Second, they allow children to "incorporate" or make familiar the content being taught, showing them it's not something extraneous to their world of experience: to imagine "helps them to see that mathematics, history, and science are not made up of alien knowledge, something out there apart from them" (Egan 1998, 62).

In sum, for Egan the overlap of narrative structure and mental images rests on certain assumptions and leads to results which show considerable affinity, as a whole, with Dewey's viewpoint: their mutual enhancement is highly emotional and engaging, allows empathic projections and identifications, facilitates meaningful retention, enables the concrete embodiment of abstractions and generalities, and, above all, constitutes a fundamental (and not merely subsidiary) modality of information coding and experience management.

Along with storytelling and its imaginatively loaded bearings, mythic understanding implies the development of other key cognitive processes. Egan focuses particular attention on the emergence of metaphorical thinking: "if we look at children's imaginative lives ... we see prodigal metaphoric invention" (Egan 2002, 94), which consist in the odd ability to project emotions over objects, to the extent that "almost anything can be seen in terms of anything else" (Egan 2008, 56). Being the tool that "lies at the heart of human intellectual inventiveness, creativity, and 
imagination" (Egan 2005, 3), Egan claims, in line with statements about cognitive linguistics, that " $\mathrm{t}$ ] his enormously fertile capacity for metaphor seems to develop as a fundamental utility for our symbolizing" (Egan 2008, 56) and "is clearly ... a foundation upon which our systematic logics of rational inquiry also rest" (Egan $2005,14)$. Hence, he calls for teachers' "stimulating and developing children's ability to recognize and use varied, rich metaphors" $(2005,57)$. Otherwise, they will never reach that divergent mental mindset required for innovative thinking.

Egan's references throughout his works to cognitive semantics and embodied cognition-and his quotations of precisely those scholars who have elaborated on the connection between imagination and metaphors in Dewey, such as M. Johnson $^{20}$ - already testify indirectly to the two pedagogues' agreement on this thematic. In addition, the very traits ascribed by the former to metaphorical thinking expressly echo the latter's beliefs: it is a process of substitution of one thing with another (a presence that reveals an absence; Egan 2005, 13); it expresses more richly what we mean (Egan 2008, 57) by expanding the power to think (Egan 2005, 15); it can be an emotive projection and establishes relations between previously unconnected things (Egan 2008, 56). Eventually, "metaphors and logic represent points on a continuum of language uses" (Egan 1998, 56), and in this respect there is no reason to posit an absolute discontinuity between different types of meaningmaking processes.

There are two other tools linked to the acquisition of oral language (mythic understanding) where, once again, Dewey's and Egan's remarks coincide significantly. On one side, Egan insists on the cognitive and formative role of play. It is a practice that "helps people free themselves from objects with which behavior is often fused" (Egan 2005, 5), thereby allowing a way of thinking about behaviors and purposes that is projected beyond the here and now. Besides, it "can also enlarge students' self-control-and their understanding of the importance of selfcontrol. In play they learn they cannot act by impulse but have to follow flexible rules" (5). These aspects are reminiscent of Dewey's stress on the essential contribution of children's leisure activities in both enhancing mental detachment from physical constraints and making them subordinate their actions, in a controlled and experimental way, to meaningful and desired goals. On the other side, Egan acknowledges the importance of exploiting educationally the "strive" element of imagination for yet unknown realities and experiences- "mystery is an important tool in developing an engagement with knowledge that is beyond the students' everyday environment. It creates an attractive sense of how much that is fascinating remains to be discovered" (5-6) - and this mirrors very closely the content of the abovementioned Dewey quotation (however occasional it may be).

Other cultural-intellectual "devices," both fostering and dependent upon imagination, accompany the mastery of oral language and subsequent operating systems. For what concerns the present comparison, two of them are still important: 


\section{Davide WeIBLE}

the appeal of heroic figures and the construction of larger meaningful wholes. In the first case, the weight given by the two authors to the topic is definitely different, both quantitatively and qualitatively. While Egan considers it a pivotal aspect of romantic understanding (that which follows and accompanies the development of literacy), ${ }^{21}$ Dewey reserves for the issue nothing more than a few passing remarks and probably would have disagreed, owing to his criticism of fancy, with the relevance placed by the former on such "heroes"' of kids' phantasies as pop stars, football players, or characters of video arcades. Nonetheless, Egan comes close to Dewey in that he claims (Egan 2005, 88) that "we can see a saint, a nurse, a scientist as heroic," and what really matters are the (positive) human qualities they embody, which represent the true target of the associative identification. The educational point is that, in contrast with subjects matters often presented as "human deserts," "mathematics, science, history, and literature are crammed with heroes" (Egan 2008, 67), so that "if we want that knowledge to engage the imagination of early adolescents we need to show it in terms of people's passions, courage, and so on" (68). Therefore, the stress placed on the human and social meaning of such emblematic persons, along with their ability to overcome difficulties through disciplined behavior, would surely meet with Dewey's favor; besides, in both theories imagination is the indispensable prerequisite for the spatial-temporal dislocation (necessary for the activation of the personification) to occur.

As for the second cognitive tool, one distinctive competence developing with philosophic understanding ${ }^{22}$ (is the skill to interpret singular objects or ideas in terms of the system or process of which they are part; namely, they are "no longer seen as more or less isolated characters and incidents ... [but] the meaning of particular events is derived from that conception of the whole" (Egan 2005, 159). At first glance this might seem to have nothing to do with imaginative thinking, since the achieved level of abstraction, with its generality and formality, does not rely anymore on the "analog world" of pictorial mental representations, but rather consists of numbers, ideas, and so on. However, if conceiving imagery only as a component of the broader capacity to imagine, the replacement of the iconicvisual format in theoretic reasoning does not suppress the cognitive properties of the figurative mind. For instance, just as the metaphorical thinking of mythic understanding is a lively "seeing as" (Egan 1998, 254) that reshapes everyday objects, and just as the wonderful aspects of things arise in romantic understanding from "everything we look upon again" (Egan 2008, 66), so in the philosophic stage "the world ... becomes re-seen as made up of vast processes-historical, social, psychological, anthropological" $(2008,73)$.

The reinterpretative activity (to see the old in new light) is grounded on an evident precondition - prior knowledge-and brings about a clear consequencewider connections. As Egan $(2005,169)$ puts it, one is forced to admit "the crucial role that expanding knowledge plays in driving the development of the abstract 
world of ideas.... Ignorance is not a condition that favors the development of imagination." When looking closer at the way theoretic thinking works, this sentence needs to be understood in a twofold way: on the one hand, the more one knows, the more his general concepts become rich, flexible, and sophisticated thanks to the challenges (anomalies) they have to face; on the other hand, since things are seen anew not for their own sake, but (bypassing usual differences) original and uncommon similarities are either detected or established between their features, then the more one knows, the more different and distant realities are likely to be classified together and new or broader conceptual wholes created (a process very akin to the construction of metaphors). But this is exactly what Dewey said of imagination when it is not confined to simple imagery: "the conscious adjustment of the new and old is imagination ... the experience enacted is human and conscious only as that which is given here and now is extended by meanings and values drawn from what is absent in fact and present only imaginatively" (Dewey 1980, 272; second emphasis mine). This definition can be fully appreciated when coupled with the following excerpt, where all factors involved in Egan's analysis (reinterpretation of the given on the basis of similar past knowledge, so as to bring it into connection with other elements, thereby expanding the system of belonging) converge and are highlighted:

Given a difficulty, the next step is suggestion of some way out-the formation of some tentative plan or project, the entertaining of some theory which will account for the peculiarities in question, the consideration of some solution for the problem. The data at hand cannot supply the solution; they can only suggest it. What, then, are the sources of the suggestion? Clearly past experience and prior knowledge. If the person has had some acquaintance with similar situations, if he has dealt with material of the same sort before, suggestions more or less apt and helpful are likely to arise. But unless there has been experience in some degree analogous, which may now be represented in imagination, confusion remains mere confusion. There is nothing upon which to draw in order to clarify it. Even when a child (or a grown-up) has a problem, to urge him to think when he has no prior experiences involving some of the same conditions, is wholly futile. (Dewey 1910, 12-13; emphases mine)

In short, there are quite a number of parallels that can be drawn between the pedagogical proposals of Dewey and Egan, which are, in turn, based on a common understanding of the functioning of imagination. Both consider it imperative to pursue a teaching methodology based on learning by imaging, whatever the subject matter in question (history, geography, literature, grammar, physics, or mathematics), ${ }^{23}$ and the effectiveness of such an approach reflects their shared belief in the constitutive imaginative nature of the human symbolic or representative capacity. 


\section{DAVide Weible}

Accordingly, what was just outlined in Egan's theory stands in sharp contrast with his own judgment of the legacy of Dewey and, however unintentionally, can be thought of as one of the most convincing positive assessments of the latter's ideas.

\section{CONCLUSIONS}

The present research aimed to demonstrate the relevance of Dewey's ideas on the value of imagination in teaching and learning, and their consistency with an important contemporary theorist. The objective has been pursued, first, by reviewing in one of his classical works the identification of the main problem of education (abstractness and indirectness of content), the solution provided (learning by doing) and how the latter, because of the impossibility of endless empirical situations of concrete experience on one side, and the nature itself of linguistic and symbolic meaning on the other, calls for an extension into a learning by imaging methodology. Second, an overview of philosophical and educational writings dealing both indirectly and explicitly with mental images (and imagination in a wider sense) has been provided, along with a description of their importance for some cognitive abilities, dimensions of human experience, and didactic practices. Finally, I outlined the key points of Egan's criticism of Dewey's contribution to present-day forms of progressivism and showed how the former's counter-proposal, despite certain contrasts, grants an equally fundamental role to imagination, thereby reducing in part the distance between their positions and, most of all, demonstrating the current validity of the latter's ideas.

Several comments have also referred in passing to the revival by cognitive linguistics and theories of embodied cognition of themes already discussed in some way in Deweyan pragmatism. ${ }^{24}$ This means that the charge of a "flawed psychology" directed at Dewey is an extreme evaluation that cannot be totally endorsed and accepted without reservations. Several examples testifying to the fecundity of Dewey's psychological insights can be found throughout the twentieth century, especially regarding the rationality of mental operations with visual images and their continuity with thinking proper on one side, ${ }^{25}$ and the close association between imagery, sensorimotor, and action-oriented processes, memory and emotion, on the other side. ${ }^{26}$

As a concluding issue, some remarks on the way imagination is understood by the two authors are essential to avoid possible misunderstandings and suggest wider contact points beyond specific pedagogical issues. As for Egan, on one side it must be underscored that, along with Dewey, he does not conflate imagination and imagery. The former is defined (Egan 2005, 220; emphasis mine) as "the ability to think of things as possible - the source of flexibility and originality in human thinking," while the ability to produce and manipulate mental images (mainly pictorial-like, but not exclusively) is thought of, more narrowly, as a particular function, among others, intervening in a specific growth stage. At the same time, they are closely connected in a chronological sense: "a crucial part of the development of 
the imagination involves the child's generation of images from words" (Egan 1998, 253; first emphasis mine). On the other side, the expression "imagination" is used by Egan as an umbrella term to cover the entire cognitive process, from the acquisition of language (and even earlier) to the achievement of a fully developed rationality.

Joined together, these two aspects reveal what can be interpreted as the development of the cognitive function of devising the possible, in the sense that the independence of imagery from actual perceptions turns subsequently into the detachment from real world of the imaginative ability and gives rise to the formal and schematic theoretic realm of eventual entities or, in Egan's terms, to "the openness to 'possibility" (Egan 1998, 122).

This is remarkable in that similar ideas-the connection of images with the dimension of the possible, the crucial role of language, and the general significance of imagination in all academic subject matter (which implies a universality blurring its boundaries with rationality and entering into the very definition of humanity) - are both detectable in Dewey's writings and explicitly recognized by some of his contemporary advocates.

As for Dewey's theorizing, in the previous analysis there have already emerged clear examples of his attention to the creative results of imagery, which can be conceived of as possibilities standing against realities. In addition, the mediating role he attributes to such transformative activity in extending humans' (and children's) power by dealing constructively with the new is evident, too, so that imagination in its broadest sense also becomes able to construct a feasible world beyond the one that is given. The connection between mental images and language has been demonstrated as well (the issues of meaning and expository definitions): the intervention of symbolic means brings about a mental duplication of the real where not-existing (yet) things or "might-be" events can be freely constructed. Eventually, for Dewey, the "de-realizing" function of imagination in its fullest potentiality is so pervasive as to characterize deeply all of the loftiest expressions of existence (morality, art, and science).

This brief excursus on some of the common assumptions underlying the educational approaches of the two authors makes it difficult to deny that both consider imagination in its wider scope a defining feature of the human being. All of this contributes again to softening Egan's criticisms of Dewey and suggests that the latter's theory was in fact not so wrong from the very beginning.

As far as Dewey is concerned, the interpretation provided regarding the relationship between imagination and possibility is confirmed by other studies. For example, Granger (2003, 53-54), when referring to the imaginative phase of thought as a "way of being" where ordinary things constitute integral wholes, sees it at the same time as "capable of extracting from existing conditions unrealized possibilities for meaning," thereby serving a reconstructive or innovative function; by disclosing alternatives, "it is a means of expanding one's everyday horizons" (58). Likewise, Macintyre Latta (2013) insists on the link between imagination and potentiality and offers considerations concerning its reconstructive (17), anticipatory, and innovative (66-69) functions that should 
be taken into account in curriculum studies and made effective in concrete teaching. Finally, Baldacchino (2009) highlights the primacy given by Dewey to "experience" in his theories of art and education, such experience becoming fully conscious only when extended through meanings imaginatively created by merging the present with the past. What is more, he critically engages with the legacy of pragmatism. By integrating in his proposal Maxine Greene's philosophy of education, ${ }^{27}$ he wants to go beyond Dewey's position and calls for a rereading of imagination from the wider horizon of the "imaginary," and as different from the fanciful while containing several features:

- it consists in anticipations of the factually impossible that overcome the constraints of the here and now and point to the future (Baldacchino 2009, 134);

- it is a "matter of being" and not simply a learning tool (7); it is a "collective human activity" (130) that exceeds the solipsistic realm of individual consciousness;

- it translates into an aesthetic attitude that subverts standardized pedagogies (117) and sympathetically opens teachers' own viewpoints to the systems of values, desires, and ideas with which students present themselves to the world (132);

- finally, by being "an investment in hope when the times are dark" (134) and an emancipative means to achieving freedom, it turns consciousness in the "location of criticality" (133) and is "the choice of difference" (141) with sociopolitical bearings.

However, when it comes to Egan, although there have been studies reaching analogous conclusions, ${ }^{28}$ one author does not adhere to this line of interpretation, and, given her importance in the contemporary philosophical-educational panorama, the critique cannot be dismissed without discussion. Moreover, it may considerably weaken the strength of the thesis I have been arguing for thus far.

Greene (1985) openly rejects the way Egan conceives imagination when talking about the abstract categories or conceptual tools used by children to make sense of fantasy stories. Instead of reducing it to a sort of preprogrammed cognitive schematization, she insists on "the capacity to create new orders in experience, to open up new possibilities, and to disclose alternative realities ... the ability to envisage the 'nonactual,' the 'unreal'" (Greene 1985, 167-168). And among the thinkers able to bring out these features, she quotes Dewey: to a certain extent, when dealing with imagination in its meaning-giving role, one can find in him "a dimension of awareness of the past and of the future, of what is not or what is not yet" $(1985,168)$. A question then arises: On the basis of Egan's description of children's cognitive tools and their mutual developmental relationship with imagination, is it possible somehow to tone down this criticism and maintain the thesis that his approach, as much as Dewey's, leans toward the possible, the unexplored, and the alternative? In Greene's words, does it open "windows in the actual and the taken-for-granted toward what might be and is not yet?" (170). 
My contention is that, without denying Greene's detection of a problematic element in Egan's framework (i.e., the function of schemes in stories) ${ }^{29}$ the notion of possibility-the overcoming of the given here and now and the transformative construction of new meaningful wholes-is not absent from his thinking, but is rather implicit, and that a teaching methodology grounded in his prescriptions does everything but prevent students from acquiring a critical attitude toward the existent. Egan's definition of imagination (Egan 2005, 220) and the characterization of philosophic understanding in terms of increased cognitive indeterminacy (Egan 1998, 122) clearly support such a claim, but other evidence can be collected throughout his writings in the distinguishing features of each cultural cognitive tool. A few passages will suffice to illustrate this point; in particular, since Greene's criticism proceeds from her desire for a social imagination as utopian thinking, one that aims to change what is wrong in deficient societies today and, by being involved in the moral life, seeks justice in the public space, ${ }^{30}$ they are meant to accentuate this sociopolitical emancipative element.

For Egan, the best defense against indoctrination "about the superiority of one's social group and the wickedness or stupidity of all others... is not crudely to censor stories, but rather to ensure that children are introduced to a great variety of them" (Egan 2008, 54). Moreover, since the comprehension and production of metaphors develops one's ability for "seeing as," ${ }_{11}$ "one of the costs of failing to develop our metaphoric capacity is the kind of literal thinking that never gets beyond its starting assumptions and presuppositions" (Egan 2008, 57). A well-stimulated sense of humor, which teaches how to deal with incongruities, enhances and enlarges our understanding as well by being "the great solvent and disrupter of excessive literalness in thinking" (Egan 2005, 24). In other words, it lays the foundations for the development of irony, which, among other functions, helps us "to recognize the limitations of our philosophic schemes.... The ironist is not going to hang or burn people or starve populations through a lack of the imagination that comes with irony's recognition that ideologies or metaphysical schemes are products of an intellectual-ordering tool out of control" (Egan 2008, 83; emphasis mine). Also, students' sense of wonder needs to be stimulated and transformed by teachers into a critical tool of intellectual inquiry, because "it is the great enemy of taking things for granted" $(2008,68)$; in this way, there emerges "the ability to imagine a world or particular circumstances that are superior in some way to the reality the students experience, to recognize those features of the adult world that sprevent their ideal's being realized, and to revolt against them" (Egan 2005, 102). Eventually, by gathering together conceptually and organically a vast range of phenomena, students learn to see themselves as agents in wider sociohistorical processes, thereby being directed by their theories "to take what steps they should to improve society" (Egan 2008, 75). At the same time, they become able to recognize anomalies not fitting certain ideological schemes and hence to acquire the attitude to question, 
revise, or discard them: at this stage it is not enough "to accept some set of inherited beliefs. One needs to establish that they are True, and if they aren't, then one must find those that are" (Egan 2005, 162-63).

However randomly selected, these citations clearly show that, although not explicitly or completely defined in a sociopolitical sense, Egan's basic program is perfectly apt to stimulate the transcendent function of pupils' cognitive tools and, in being consistent with the abovementioned scholarly readings of Dewey (Greene's position included), bring these two great educational thinkers closer together.

\section{Notes}

1. See Jerome Bruner, “After John Dewey, What?" in On Knowing: Essays for the Left Hand, edited by Jerome Bruner, 113-29 (Cambridge, MA: Harvard University Press, 1962/1997); John Dewey, “My Pedagogic Creed," School Journal 54 (1897): 77-80.

2. See Kieran Egan, Getting It Wrong from the Beginning (New Haven, CT: Yale University Press, 2002).

3. John Dewey, Democracy and Education (New York: Macmillan, 1916); David T. Hansen, ed., John Dewey and Our Educational Prospect: A Critical Engagement with Dewey's Democracy and Education (Albany, NY: SUNY Press, 2006).

4. John Dewey, How We Think (Boston: D.C. Heath \& Company, 1910).

5. John Dewey, Logic: The Theory of Inquiry (New York: Henry Holt and Company, 1938/1939).

6. Abbreviations for The Collected Works of John Dewey used throughout: The Early Works (1882-1898): EW; The Middle Works (1899-1924): MW; The Later Works (1925-1953): LW.

7. John Dewey, Human Nature and Conduct (New York: Henry Holt and Company, 1922/1928).

8. Cf. David I. Waddington, Troublesome Sentiments: The Origins of Dewey's Antipathy to Children's Imaginative Activities," Studies in Philosophy and Education 29, no. 4 (2010): 31-64.

9. See J. J. Chambliss, “John Dewey's Philosophy of Education Before Democracy and Education," Education and Culture 19, no. 1 (2003): 1-7.

10. John Dewey, Psychology (New York: Harper \& Brothers, 1887/1890).

11. Cf. Frederik Stjernfelt, Diagrammatology: An Investigation on the Borderlines of Phenomenology, Ontology, and Semiotics (Dordrecht: Springer, 2007). For an analysis of the influence of Peirce on Dewey with a focus on both educational issues and the problem of how new learning arises from previous knowledge, see Richard S. Prawat, "Dewey, Peirce, and the larning Paradox," American Educational Research Journal 36, no. 1 (1999): 47-76; and Prawat, "The Two Faces of Deweyan Pragmatism: Inductionism versus Social Constructivism," Teachers College Record 102, no. 4 (2000): 805-40.

12. Steven Fesmire, John Dewey and Moral Imagination (Bloomington: Indiana University Press, 2003).

13. Cf. also John Dewey and Evelyn Dewey, Schools of Tomorrow (New York: E.P. Dutton, 1915), 84-87.

14. For the connection between imagination and dramatic or story-structured deliberation, see also Fesmire, John Dewey and Moral Imagination, 2003. 
15. For the importance of play in revising approaches to curriculum design, with a central focus on Dewey's imagination, see Margaret Macintyre Latta, Curricular Conversations: Play is the (Missing) Thing (New York: Routledge, 2013).

16. See Thomas M. Alexander, "Pragmatic Imagination," Transactions of the Charles S. Pierce Society 26, no. 3 (1990): 325-48; Prawat, “The Value of Ideas: The Immersion Approach to the Development of Thinking," Educational Researcher 20, no. 2 (1991): 3-10+30; and Prawat, "The Value of Ideas: Problems Versus Possibilities in Learning," Educational Researcher 22, no. 6 (1993): 5-16.

17. E.g., Lev S. Vygostky, The Collected Works of L. S. Vygostky, edited by Robert W. Rieber and J. Wollock, vol. 3 (New York: Plenum, 1997); Merlin Donald, Origins of the Modern Mind: Three Stages on the Evolution of Culture and Cognition (Cambridge, MA: Harvard University press, 1991); Donald, A Mind So Rare: The Evolution of Human Consciousness (New York: Norton, 2001); Alex Kozulin, Psychological Tools: A Sociocultural Approach to Education (Cambridge, MA: Harvard University Press, 1998); James V. Wertsch, Vygotsky and the Social Formation of Mind (Cambridge, MA: Harvard University Press, 1988); Voices of the Mind: A sociocultural Approach to Mediated Action (Cambridge, MA: Harvard University Press, 1991); and Wersch, Mind as Action (New York: Oxford University Press, 1997).

18. For a full and detailed treatment of the "cognitive-tools theory," see Egan, The Educated Mind, 1997/1998.

19. Cf. also Kieran Egan, The Educated Mind: How Cognitive Cools Shape Our Understanding (Chicago: University of Chicago Press, 1997/1998), 33-70; and Egan, An Imaginative Approach to Teaching (San Francisco: Jossey Bass, 2005), 1-35.

20. Cf., for instance, Egan, The Educated Mind, 1998, 56.

21. Cf. Egan, The Educated Mind, 1998, 71-103; Egan, An Imaginative Approach to Teaching, 2005, 77-108; and Eagan, The Future of Education (New Haven, CT: Yale University Press, 2008), 62-70.

22. Cf. Egan, The Educated Mind, 1998, 104-136; Egan, An Imaginative Approach, 2005, 151-169; and Egan, The Future of Education, 2008, 70-80.

23. In this respect, cf. Egan, An Imaginative Approach to Teaching, 2005 for concrete examples divided for types of understanding.

24. For more insights, see Mark Johnson, "Knowing Through the Body," Philosophical sychology 4, no. 1 (1991); Johnson, Moral Imagination (Chicago: University of Chicago Press, 1993); and Johnson, The Meaning of the Body: Aesthetics of Human Understanding (Chicago: University of Chicago Press, 2007).

25. Cf. Rudolf Arnheim, Visual Thinking (Berkeley: University of California Press, 1969).

26. Neuropsychological evidence has been provided thereupon; cf. Allan Paivio, Mental Representations: A Dual Coding Approach (Oxford, UK: Oxford University Press, 1986) and Paivio, Mind and Its Evolution: A Dual Coding Theoretical Interpretation (Mahwah, NJ: Lawrence Erlbaum Associates, Inc., 2006).

27. Cf. Maxine Greene, "Creating, Experience, Sense-Making: Art Worlds in Schools," Journal of Aesthetic Education 21, no. 4 (1987): 11-23 and Greene, Releasing the Imagination, 2000.

28. On his correct identification of the connection between possibility and imaginative thinking, see Robert Fitzgerald and Thomas W. Nielsen, Imaginative Practice, Imaginative Inquiry. Proceedings of the Sixth International Conference on Imagination and Education (Canberra: University of Canberra, 2008); Mark Fettes, “The TIEs That Bind: How Imagination Grasps the World," in Engaging Imagination and Developing Creativity in Education, edited by Kieran Egan and Krystina Madej, 2-16 (Newcastle upon Tyne: Cambridge Scholars Publishing, 2010). 


\section{DAVIDE WeIBLE}

29. Cf. also his own response: Kieran Egan, "Imagination and Learning: A Response to Maxine Greene," Teachers College Record 87, no. 2 (1985): 172-74.

30. Cf. Greene, Releasing the Imagination, 2000.

31. Cf. Egan, The Educated Mind, 1998, 254).

\section{BIBLIOGRAPHY}

Alexander, Thomas M. "Pragmatic Imagination." Transactions of the Charles S. Peirce Society 26, no. 3 (1990): 325-48.

Arnheim, Rudolf. Visual Thinking. Berkeley: University of California Press, 1969. Baldacchino, John. Education Beyond Education. Self and the Imaginary in Maxine Greene's Philosophy. New York: Peter Lang, 2009.

Bruner, Jerome. On Knowing. Essays for the Left Hand. Cambridge, MA: Harvard University Press, 1962/1997.

Chambliss, J. J. “John Dewey's Idea of Imagination in Philosophy and Education." Journal of Aesthetic Education 25, no. 4 (1991): 43-49.

-_- "John Dewey's Philosophy of Education Before Democracy and Education." Education and Culture 19, no. 1 (2003): 1-7.

Cochran, Molly, ed. The Cambridge Companion to Dewey. Cambridge: Cambridge University Press, 2010.

Dewey, John. Art as Experience. New York: Perige Books, 1934/1980.

- - - The Collected Works of John Dewey, 1882-1953 (37 vols.). Edited by Jo Ann

Boydston. Carbondale: Southern Illinois University Press, 1969-1991.

-_- Democracy and Education. New York: The Macmillan Company, 1916.

- - - Experience and Education. New York: Kappa Delta Pi, 1938.

_-_. Experience and Nature. London: George Allen and Unwin, Ltd, 1925/1929.

-_- How We Think. Boston: D.C. Heath \& Company, 1910.

-_- Human Nature and Conduct. New York: Henry Holt and Company, 1922/1928.

-_- Logic: The Theory of Inquiry. New York: Henry Holt and Company, 1938/1939.

——_. "My Pedagogic Creed." School Journal 54 (1897): 77-80.

_-_. Psychology. New York: Harper \& Brothers, 1887/1890.

Dewey, John, and Evelyn Dewey. Schools of Tomorrow. New York: E.P. Dutton, 1915. Donald Merlin. A Mind So Rare: The Evolution of Human Consciousness. New York: Norton, 2001.

-_- Origins of the Modern Mind: Three Stages in the Evolution of Culture and Cognition. Cambridge, MA: Harvard University Press, 1991.

Egan, Kieran. The Educated Mind. How Cognitive Tools Shape Our Understanding. Chicago: University of Chicago Press, 1997/1998.

-_- The Future of Education. New Haven, CT: Yale University Press, 2008.

- - - Getting It Wrong from the Beginning. New Haven \& London: Yale University Press, 2002.

-_- An Imaginative Approach to Teaching. San Francisco: Jossey-Bass, 2005. 
-_- Imagination and Education. New York: Teachers College Press, 1988.

_-_. "Imagination and Learning: A Response to Maxine Greene." Teachers College Record 87, no. 2 (1985): 172-74.

- - - Imagination in Teaching and Learning: The Middle School Years. Chicago: University of Chicago Press, 1992.

Fesmire, Steven. John Dewey and Moral Imagination. Bloomington: Indiana University Press, 2003.

- - - "Morality as Art: Dewey, Metaphor, and Moral Imagination." Transactions of the Charles S. Peirce Society 35, no. 3 (1999): 527-50.

Fettes, Mark. “The TIEs That Bind: How Imagination Grasps the World." In Engaging Imagination and Developing Creativity in Education, edited by Kieran Egan, Krystina Madej, 2-16. Newcastle upon Tyne: Cambridge Scholars Publishing, 2010.

Fitzgerald, Robert, and Thomas W. Nielsen. Imaginative Practice, Imaginative Inquiry. Proceedings of the Sixth International Conference on Imagination and Education. Canberra: University of Canberra, 2008.

Granger, David A. "Expression, Imagination, and Organic Unity: John Dewey's Aesthetics and Romanticism." The Journal of Aesthetic Education 37, no. 2 (2003): 46-60.

Greene, Maxine. "Creating, Experiencing, Sense-Making: Art Worlds in Schools." Journal of Aesthetic Education 21, no. 4 (1987): 11-23.

- - - "Imagination and Learning: A Reply to Kieran Egan." Teachers College Record 87, no. 2 (1985): 167-71.

- - Releasing the Imagination: Essays on Education, the Arts, and Social Change. San Francisco: Jossey-Bass, 2000.

Hansen, David T., ed. John Dewey and Our Educational Prospect: A Critical Engagement with Dewey's Democracy and Education. Albany, NY: SUNY Press, 2006.

Johnson, Mark. "Cognitive science and Dewey's theory of mind, thought, and language." In The Cambridge Companion to Dewey, edited by Molly Cochran, 123-144. Cambridge, UK: Cambridge University Press, 2010.

_-_. "Knowing Through the Body." Philosophical Psychology 4, no. 1 (1991): 3-18.

- - . The Meaning of the Body: Aesthetics of Human Understanding, Chicago: University of Chicago Press, 2007.

-_- Moral Imagination. Chicago: University of Chicago Press, 1993.

Kozulin, Alex. Psychological Tools: A Sociocultural Approach to Education. Cambridge, MA: Harvard University Press, 1998.

Macintyre Latta, Margaret. Curricular Conversations: Play is the (Missing) Thing. New York: Routledge, 2013.

Paivio, Allan. Mental Representations: A Dual Coding Approach. Oxford, UK: Oxford University Press, 1986.

-_- Mind and Its Evolution: A Dual Coding Theoretical Interpretation. Mahwah, NJ: Lawrence Erlbaum Associates, Inc., 2006.

Prawat, Richard S. "Dewey, Peirce, and the Learning Paradox." American Educational Research Journal 36, no. 1 (1999): 47-76. 


\section{Davide Weible}

- - - "The Two Faces of Deweyan Pragmatism: Inductionism versus Social Constructivism.” Teachers College Record 102, no. 4 (2000): 805-40.

- - - "The Value of Ideas: The Immersion Approach to the Development of Thinking." Educational Researcher 20, no. 2 (1991): 3-10+30.

- _- "The Value of Ideas: Problems Versus Possibilities in Learning." Educational Researcher 22, no. 6 (1993): 5-16.

Puolakka, Kalle. "Naturalism and Metaphors: Towards a Rortian Pragmatist Aesthetics." European Journal of Pragmatism and American Philosophy 3, no. 1 (2009): 163-75.

-_- Relativism and Intentionalism in Interpretation: Davidson, Hermeneutics, and Pragmatism. Lanham, MD: Lexington Books, 2011.

Stjernfelt, Frederik. Diagrammatology: An Investigation on the Borderlines of Phenomenology, Ontology, and Semiotics. Dordrecht: Springer, 2007.

Vygotsky, Lev S. The Collected Works of L. S. Vygotsky. Edited by Robert W. Rieber and J. Wollock, Vol. 3. New York: Plenum, 1997.

Waddington, David I. “Troublesome Sentiments: The Origins of Dewey's Antipathy to Children's Imaginative Activities." Studies in Philosophy and Education 29, no. 4 (2010): 351-64.

Wertsch, James V. Mind as Action. New York: Oxford University Press, 1997.

-_- Voices of the Mind: A Sociocultural Approach to Mediated Action. Cambridge, MA: Harvard University Press, 1991.

- - - Vygotsky and the Social Formation of Mind. Cambridge, MA: Harvard University Press, 1988.

Davide Weible is a $\mathrm{PhD}$ candidate in the Department of Semiotics at Tartu University. Email: davideweible@hotmail.com 